\title{
Avaliação da qualidade físico-química e microbiológica de mel comercializado
}

\author{
Evaluation of physical-chemical and microbiological quality of marketed honey
}

Rayanne Ribeiro \& Karina Ramirez Starikoff*

Universidade Federal da Fronteira Sul, Realeza, PR, Brasil. *Autor para correspondência: karina.starikoff@uffs.edu.br.

Submissão:16/01/2018 / Aceite: 19/06/2018

\begin{abstract}
RESUMO
O mel é um produto naturalmente produzido por abelhas e, devido a sua composição, possui sabor característico e alto valor nutritivo. Seu uso é relatado desde a antiguidade e, a cada dia ganha novos mercados consumidores. A exigência por produtos de qualidade disponíveis ao consumo humano reflete a necessidade de uma maior fiscalização durante o processo de produção. $\mathrm{O}$ objetivo desta pesquisa foi avaliar a qualidade físico-química e microbiológica de 22 amostras de méis com registro de inspeção e de comércio informal, de diferentes municípios da região Sul do Brasil. Foram analisados os parâmetros: acidez total, pH, hidroximetilfurfural, sólidos insolúveis, atividade diastásica, reações de Fiehe, Lugol, Lund e a presença de bolores e leveduras. Quanto às características físico-químicas, $54,54 \%$ das amostras apresentaram alguma inconformidade com os parâmetros estabelecidos pela legislação. Apesar da legislação não fazer exigências quanto à realização de análises microbiológicas, 45,45\% das amostras apresentaram a presença de bolor e levedura.
\end{abstract}

PALAVRAS-CHAVE: segurança alimentar, inspeção de produtos de origem animal, mercado informal.

\begin{abstract}
Honey is a product naturally produced by bees and, due to its composition, it has a characteristic flavor and high nutritional value. Its use is known since antiquity and each day it conquers new consumer markets. The demand for quality products available for human expenditure reflects the need for better supervision during the production process. The goal for this research was to evaluate the physio-chemical and microbiological quality of 22 honey samples with inspection and informal commerce registers in different cities in Paraná, Rio Grande do Sul and Santa Catarina. The following parameters were analyzed: total acidity, pH, insoluble solids, diastase activity, hydroxymethylfurfural, Fiehe, Lugol, Lund reactions, and the presence of mold and yeast. As to the physical-chemical characteristics, $54.54 \%$ of the samples presented some shortcoming with the parameters established by the legislation. Although the law doesn't demand microbiological analyses, $45.45 \%$ of the samples presented mold and yeast.

KEYWORDS: food safety, monitoring of products of animal origin, informal market.
\end{abstract}

\section{INTRODUÇÃO}

Segundo a legislação brasileira (BRASIL 2000) mel é um produto naturalmente produzido por abelhas melíferas e é obtido a partir do néctar das flores, de secreções de partes vivas de plantas ou de excreções de insetos sugadores de partes vivas de plantas. É composto por uma solução de açúcares concentrados, principalmente glicose e frutose, os quais influenciam diretamente sua doçura, além de possuir enzimas (invertase, amilase e glico-oxidase), aminoácidos, ácidos orgânicos, minerais, pigmentos e grãos de pólen (CRANE 1987, BRASIL 2000). Por possuir diferentes origens florais, sua composição físico-química e sensorial pode sofrer algumas variações e, assim, ser classificado de acordo com sua origem botânica e forma de obtenção (BRASIL 2000).

Devido sua composição, além da utilização do mel na alimentação, existem estudos que comprovam suas propriedades terapêuticas, antimicrobianas, antioxidantes e prebióticas (SILVA et al. 2006). IOIRICH (1981) descreve o uso do mel na antiguidade atribuindo propriedades médico-profiláticas, bem como as propriedades medicinais atribuídas ao uso da cera, de própole, do pólen e da geleia real.

A apicultura brasileira é uma atividade agrícola que produz mel de alta qualidade devido a espécie 
utilizada na exploração, Apis mellifera, também conhecida como abelha africanizada. Estas abelhas apresentam a rusticidade como uma de suas principais características, o que diminui a utilização de drogas veterinárias no seu manejo. Essa particularidade favorece o desenvolvimento e promoção de produtos com grande aceitação no mercado externo (SEBRAE 2007).

No ano de 2013, a apicultura brasileira atingiu uma produção total de 35.635 toneladas e um aumento de 4,2\%, em relação ao ano de 2012 (FAO 2013, IBGE 2013). A região Sul foi responsável por $50,2 \%$ da produção, tendo o Rio Grande do Sul como maior produtor do país (20,6\%), seguido pelos estados do Paraná (15,7\%) e Santa Catarina (13,8\%) (IBGE 2013). Segundo dados do IBGE (2011), o consumo alimentar médio per capita de mel/rapadura/açúcar de mesa e outros adoçantes é de $0,9 \mathrm{~g} / \mathrm{dia}$. Sendo que o sexo masculino consome $0,9 \mathrm{~g} / \mathrm{dia}$ e para o sexo feminino é de $0,8 \mathrm{~g} / \mathrm{dia}$.

Mesmo tratando-se de uma atividade reconhecidamente desenvolvida por pequenos e médios apicultores, a cadeia produtiva apícola vem ganhando força nos últimos anos com a crescente produção e exportação de produtos, através do desenvolvimento de manejos aplicando as boas práticas apícolas (SEBRAE 2007, ARRUDA et al. 2011). Esse aumento na exportação também pode justificar-se pelo aumento da demanda de países estrangeiros que, a partir do ano de 2008, encerrou o embargo ao mel brasileiro pela Comunidade Europeia (SEBRAE 2011). Conforme dados divulgados pela Associação Brasileira dos Exportadores de Mel - ABEMEL (2015), no ano de 2014, o Brasil passou a ocupar o 8 lugar no ranking dos maiores exportadores, com um volume de 25.317 toneladas, movimentando cerca de 98.576.057,00 dólares.

Para atender as exigências sanitárias do mercado interno e externo desta cadeia produtiva, no Brasil, o Serviço de Inspeção Federal (S.I.F.), que está vinculado ao Departamento de Inspeção de Produtos de Origem Animal (DIPOA), é responsável por assegurar a qualidade dos produtos de origem animal, comestíveis e não comestíveis. Este departamento para inspeção de produtos de origem animal conta com 5.000 estabelecimentos, com o selo do S.I.F. (BRASIL 2016).

A produção e comercialização do mel de $A$. mellifera é regulamentada pela Instrução Normativa no 11, de 20 de outubro de 2000 - IN11/2000, e pela Portaria no 6 , de 25 de julho de 1985 do Ministério da Agricultura, Pecuária e Abastecimento - Portaria6/MAPA, que estabelecem os padrões para garantir a identidade e os requisitos mínimos de qualidade do mel destinado ao consumo humano e as normas higiênico-sanitárias e tecnológicas para mel, cera de abelhas e derivados.

Assim, o objetivo desta pesquisa foi realizar análises físico-químicas e microbiológicas para averiguar a qualidade de méis que são comercializados em diferentes municípios da Região Sul do país.

\section{MATERIAL E MÉTODOS}

Foram utilizadas 22 amostras de méis de abelhas $A$. mellifera: dez amostras com registro no Serviço de Inspeção Federal e Serviço de Inspeção Municipal e 12 não inspecionadas, provenientes dos estados do Paraná, Rio Grande do Sul e Santa Catarina. As amostras foram adquiridas no comércio local, como em mercados, farmácias e outros estabelecimentos, além do comércio informal, sendo adquiridas diretamente com produtores de mel. As análises foram realizadas nos meses de janeiro a abril de 2016, nos Laboratórios de Química Orgânica e Microbiologia, da Universidade Federal da Fronteira Sul, Campus Realeza, PR.

Os parâmetros físico-químicos analisados para a caracterização das amostras estão de acordo com as normas para análise de alimentos, descritos pelo Instituto Adolfo Lutz - IAL (2008). Foram realizados: determinação da acidez total (174/IV Méis), pH (174/IV Méis), hidroximetilfurfural (175/IV Méis), sólidos insolúveis (180/IV Méis), atividade diastásica (181/IV Méis) e umidade (173/IV Méis), além das reações de Lund (182/IV Méis), Fiehe (183/IV Méis) e Lugol (184/IV Méis). A determinação de sólidos insolúveis em água por gravimetria foi adaptada a partir das normas do IAL (2008), com a substituição do cadinho de vidro por funil de Buchner com a utilização de Papel de Filtro Quantitativo JP 40 Faixa Branca. Todas as análises foram realizadas em triplicatas, exceto para a determinação do teor de hidroximetilfurfural e atividade diastásica, que foram em duplicata.

Para a avaliação microbiológica, foram transferidas 25 gramas de cada amostra para $225 \mathrm{~mL}$ de solução salina peptonada a $0,1 \%$, formando a diluição $10^{-1}$. A partir desta, fez-se diluições decimais seriadas para a obtenção das concentrações $10^{-2}$ e $10^{-3}$. De cada diluição $\left(10^{-1}\right.$ a $\left.10^{-3}\right)$ plaquearam-se alíquotas de $1 \mathrm{~mL}$ em meio ágar batata dextrose, com semeadura em superfície. As placas foram incubadas em estufa bacteriológica a $25^{\circ} \mathrm{C}$, durante 5 dias, para a contagem total de bolores e leveduras.

Os dados obtidos foram organizados em tabelas após cálculo de média e desvio padrão pelo uso do software Microsoft Excel 2011, e foi feita uma análise estatística descritiva dos dados. 
Os resultados dos parâmetros físico-químicos foram comparados com os valores estabelecidos pela IN11/2000 e pela Portaria6/MAPA.

\section{RESULTADOS E DISCUSSÃO}

As informações dispostas nos rótulos das 22 amostras de méis foram analisadas de acordo a Resolução - RDC no 259, de 20 de setembro (ANVISA 2002), que dispõe sobre o Regulamento Técnico sobre Rotulagem de Alimentos Embalados.

Sete amostras apresentavam Registro de Inspeção Federal (S.I.F.), três o Registro de Inspeção Municipal (S.I.M.) e 12 amostras eram produtos do comércio informal. Além disso, sete amostras foram provenientes do Paraná, duas do Rio Grande do Sul e 13 de Santa Catarina.

Os resultados das médias e desvios padrão obtidos nas análises físico-químicas para as 22 amostras analisadas estão apresentadas na Tabela 1.

Tabela 1. Análises físico-químicas de méis provenientes de diferentes municípios da região Sul do Brasil.

Table 1. Physical-chemical analysis of honey varieties from different municipalities in the South Region of Brazil.

\begin{tabular}{|c|c|c|c|c|c|c|c|c|c|c|c|c|c|c|c|}
\hline \multirow[b]{2}{*}{ Amostras } & \multicolumn{2}{|c|}{ AT } & \multicolumn{2}{|c|}{$\mathrm{pH}$} & \multicolumn{2}{|c|}{ HMF } & \multicolumn{2}{|c|}{ SI } & \multicolumn{2}{|c|}{$A D$} & \multicolumn{2}{|c|}{$U$} & \multirow[t]{2}{*}{$\mathrm{RLU}$} & \multirow[t]{2}{*}{$\mathrm{RF}$} & \multirow[t]{2}{*}{$\mathrm{RL}$} \\
\hline & $M$ & DP & $M$ & DP & $M$ & DP & $M$ & DP & $M$ & DP & $M$ & DP & & & \\
\hline 1 & 29,28 & 1,00 & 4,50 & 0,01 & 13,18 & 9,04 & 0,04 & 0,06 & 16,72 & 1,31 & 16,80 & 1,15 & + & - & - \\
\hline 2 & 35,89 & 0,31 & 4,12 & 0,20 & 5,16 & 1,17 & 0,08 & 0,03 & 13,07 & 0,80 & 15,30 & 0,70 & + & - & - \\
\hline 3 & 44,02 & 0,40 & 3,32 & 0,43 & 27,09 & 5,36 & 0,05 & 0,04 & 12,52 & 0,74 & 16,30 & 1,01 & + & - & - \\
\hline 4 & 28,60 & 1,07 & 4,03 & 0,38 & 21,14 & 1,61 & 0,07 & 0,07 & 4,40 & 1,35 & 16,70 & 0,70 & + & + & - \\
\hline 5 & 54,17 & 1,52 & 3,33 & 0,37 & 2,43 & 1,19 & 0,07 & 0,05 & 17,71 & 1,47 & 18,90 & 0,12 & - & - & - \\
\hline 6 & 29,66 & 1,00 & 2,70 & 0,34 & 6,17 & 3,77 & 0,23 & 0,37 & 6,39 & 0,19 & 16,70 & 0,31 & - & + & + \\
\hline 7 & 19,76 & 0,33 & 3,54 & 0,45 & 23,35 & 19,77 & 0,16 & 0,09 & 3,43 & 0,03 & 14,30 & 0,95 & + & + & - \\
\hline 8 & 47,24 & 0,62 & 3,50 & 0,05 & 25,86 & 19,97 & 0,09 & 0,01 & 9,38 & 0,00 & 17,30 & 0,12 & + & - & - \\
\hline 9 & 29,06 & 1,27 & 3,64 & 0,09 & 22,34 & 15,22 & 0,11 & 0,03 & 8,68 & 1,40 & 15,10 & 0,76 & + & - & - \\
\hline 10 & 43,91 & 0,82 & 3,27 & 0,20 & 12,48 & 10,61 & 0,10 & 0,04 & 17,16 & 0,69 & 16,90 & 0,61 & + & - & - \\
\hline 11 & 49,24 & 0,63 & 3,32 & 0,03 & 20,18 & 11,07 & 0,10 & 0,02 & 16,23 & 0,62 & 17,50 & 0,50 & + & - & - \\
\hline 12 & 33,57 & 0,37 & 3,52 & 0,11 & 19,65 & 9,64 & 0,10 & 0,01 & 17,71 & 1,47 & 16,50 & 0,50 & + & - & - \\
\hline 13 & 57,16 & 0,22 & 3,53 & 0,02 & 37,50 & 1,68 & 0,08 & 0,03 & 14,58 & 2,95 & 15,50 & 1,22 & + & - & - \\
\hline 14 & 53,61 & 0,88 & 4,08 & 0,29 & 11,69 & 5,45 & 0,07 & 0,03 & 12,82 & 1,16 & 17,10 & 0,50 & + & - & - \\
\hline 15 & 32,92 & 0,54 & 3,36 & 0,38 & 86,75 & 10,82 & 0,11 & 0,05 & 2,61 & 1,02 & 14,70 & 0,50 & + & - & - \\
\hline 16 & 63,35 & 1,25 & 3,34 & 0,03 & 19,22 & 2,65 & 0,11 & 0,05 & 18,82 & 1,66 & 18,10 & 0,12 & + & - & - \\
\hline 17 & 31,68 & 0,61 & 3,41 & 0,05 & 15,72 & 6,27 & 0,02 & 0,02 & 9,50 & 2,27 & 19,10 & 0,31 & + & + & + \\
\hline 18 & 44,26 & 0,33 & 3,36 & 0,04 & 11,19 & 2,73 & 0,06 & 0,05 & 10,94 & 0,84 & 18,70 & 0,50 & + & - & - \\
\hline 19 & 22,14 & 1,05 & 3,49 & 0,08 & 11,66 & 2,95 & 0,04 & 0,04 & 7,41 & 1,64 & 16,50 & 0,12 & + & - & - \\
\hline 20 & 28,41 & 0,08 & 3,31 & 0,11 & 43,76 & 49,60 & 0,12 & 0,08 & 12,32 & 9,10 & 16,70 & 0,31 & + & - & - \\
\hline 21 & 24,20 & 2,37 & 3,53 & 0,15 & 8,84 & 2,00 & 0,06 & 0,06 & 17,65 & 0,00 & 18,50 & 0,12 & + & - & - \\
\hline 22 & 29,77 & 0,33 & 3,64 & 0,11 & 7,43 & 5,92 & 0,04 & 0,03 & 15,14 & 5,10 & 17,90 & 0,12 & + & - & - \\
\hline
\end{tabular}

Nota: $\mathrm{AT}=$ Acidez total $(\mathrm{mEq} / \mathrm{kg}) ; \mathrm{pH}=$ Potencial hidrogêniônico; HMF = Hidroximetilfurfural $(\mathrm{mg} / \mathrm{kg}) ; \mathrm{SI}=$ Sólidos insolúveis (\%); $\mathrm{AD}=$ Atividade diastásica (Unidades na escala Gothe); U = Umidade (\%); RLU = Reação de Lund; RF = Reação de Fiehe; RL = Reação de Lugol; M = Média; DP = Desvio padrão; + = Positvo; - = Negativo; Legislação: IN11/2000 e Portaria6/1985.

Vários ácidos orgânicos estão presentes no mel, em diferentes quantidades e conferem a característica de produtos com pH acidificado. O ácido glicônico constitui aproximadamente de 70 a $90 \%$ do total destes ácidos. Ele é resultado da ação da enzima glicose-oxidase, que é produzida pelas glândulas hipofaríngeas das abelhas, sobre a glicose. Esta acidez é a responsável pela estabilidade do mel frente a ação de microrganismos (CRANE 1987, KOBLITZ 2008).

A IN11/2000 estipula valores de acidez de até $50 \mathrm{mEq} / \mathrm{kg}$ (BRASIL 2000). A acidez total das amostras analisadas apresentou um valor mínimo de $19,76 \mathrm{mEq} / \mathrm{kg}$ (amostra 7) e máxima de 63,35 mEq/kg (amostra 16). E três amostras (13,63\%) apresentaram valores superiores, com médias de $54,17 \mathrm{mEq} / \mathrm{kg}$ (amostras 5); 
$57,16 \mathrm{mEq} / \mathrm{kg}$ (amostra 13) e 63,35 mEq/kg (amostra 16). Segundo KOBLITZ (2008) amostras que tenham sofrido adição intencional de acidulantes ou açúcares obtidos por hidrólise ácida, podem apresentar valores para acidez acima do estabelecido pela legislação.

DIAS et al. (2009), ao analisarem seis amostras de méis de Londrina e região, obtiveram valor mínimo de 17,69 mEq/kg e valor máximo de $52,57 \mathrm{mEq} / \mathrm{kg}$, com apenas uma amostra acima do permitido pela legislação. CHAVES et al. (2015), ao analisarem 20 amostras em Teresina, Piauí, encontraram média para acidez total de $42 \mathrm{mEg} / \mathrm{kg}$, com $25 \%$ de amostras em desacordo com a legislação. WELKE et al. (2008) analisaram méis de floradas de dois anos consecutivos da região noroeste do Estado do Rio Grande do Sul e, para as 36 amostras analisadas, o resultado dos méis da florada de 2005 ficou com média de $30,1 \mathrm{mEq} / \mathrm{kg}$, enquanto que para os méis da florada de 2006 a média foi de $39,8 \mathrm{mEq} / \mathrm{kg}$.

Para os resultados de $\mathrm{pH}$, os valores mínimos e máximos variaram de 2,70 (amostra 6) a 4,50 (amostra 1), respectivamente. Ao comparar os resultados encontrados do $\mathrm{pH}$ com o estabelecido pela Portaria 6/MAPA (BRASIL 1985), verificou-se que 9,09\% das amostras (amostras 6 e 10) estão em desacordo com o limite padrão que vai de 3,30 a 4,60. Esta variação de pH apresenta-se próxima aos valores obtidos por PINTO \& LIMA (2010) que, ao avaliarem 26 amostras de méis da região do Vale do Aço, $\mathrm{MG}$, obtiveram resultados de $\mathrm{pH}$ entre 2,41 a 4,53. PEREIRA et al. (2015), ao analisarem o pH de 10 amostras de méis, no município de Maringá, PR, obtiveram resultados de 2,86 a 4,17. LIRIO et al. (2015) ao analisarem 24 amostras de méis silvestres comercializados no Estado do Rio de Janeiro, obtiveram resultados para pH entre 3,80 a 4,90, que são valores próximos aos encontrados por ANDRIGHETTO et al. (2009), com pH de 3,79 a 4,67, na cidade de Santo Augusto, RS, com quatro amostras de méis.

A desidratação de hexoses (glicose e frutose) na presença de um ácido, resulta na formação de hidroximetilfurfural (HMF), sendo este considerado um produto natural do mel. Em altas temperaturas as concentrações de HMF aumentam rapidamente, tornando-o assim, um indicador de qualidade, seja por indicativo de aquecimento, longa estocagem ou adulteração (CRANE 1987, KOBLITZ 2008).

Conforme a IN $/ 2000$, o teor de HMF deve ser de no máximo $60 \mathrm{mg} / \mathrm{kg}$ (BRASIL 2000). Desta forma, das 22 amostras analisadas, apenas a amostra 15 (4,54\%), apresentou-se fora do padrão estabelecido. $O$ valor mínimo para HMF foi de 3,05 mg/kg (amostra 5) e o valor máximo foi de 92,94 mg/kg (amostra 15). Segundo CRANE (1987), alguns méis provenientes de climas tropicais podem ser considerados naturalmente deteriorados por possuírem altos valores de HMF. Isso justifica-se pelas elevadas temperaturas ambientais dentro das colmeias e não pela adulteração ou superaquecimento proposital do produto.

OLIVEIRA \& SANTOS (2011), ao caracterizarem amostras de méis de A. mellifera provenientes do município de Mauriti, CE, obtiveram um valor médio para HMF de 49,93 mg/kg e, uma variação de 6,08 a $194,74 \mathrm{mg} / \mathrm{kg}$. MARCHINI et al. (2005) ao analisarem amostras de diferentes floradas no Estado de São Paulo, encontraram valores para HMF de mel silvestre com média de $19,30 \mathrm{mg} / \mathrm{kg}$ e um intervalo de variação de 1,00 a $122,00 \mathrm{mg} / \mathrm{kg}$, enquanto que para mel de eucalipto a média ficou em $17,40 \mathrm{mg} / \mathrm{kg}$ e o intervalo de variação de 0,30 a $207,20 \mathrm{mg} / \mathrm{kg}$. Das 121 amostras analisadas pelos autores, $5,8 \%$ apresentaram-se com resultados fora do limite para HMF. MORETI et al. (2009) também verificaram a variação nos resultados de HMF entre 52 amostras de diferentes municípios do Estado do Ceará, os valores da variação ficaram entre 1,0 a $126,5 \mathrm{mg} / \mathrm{kg}$ e, o valor médio foi de $15,7 \mathrm{mg} / \mathrm{kg}$. Cinco amostras apresentaram-se fora do limite máximo de $60 \mathrm{mg} / \mathrm{kg}$.

A quantificação dos sólidos insolúveis é uma importante maneira para determinar o controle higiênico do mel, pois está correlacionado à presença de resíduos como cera, pernas e asas de abelhas e, outros materiais provenientes do processamento do mel.

Segundo a IN11/2000, os méis podem apresentar uma quantidade máxima de $0,1 \%$ de sólidos insolúveis (BRASIL 2000). A variação encontrada foi de 0,02\% (amostra 17) a $0,23 \%$ (amostra 6). As amostras $6,7,9,15,16$ e $20(27,27 \%)$ apresentaram-se com valores superiores ao permitido. Resultados semelhantes foram encontrados por ARAÚJO (2006) e SILVA et al. (2006), que ao analisarem dez amostras do município de Cratos, CE, obtiveram uma variação de $0,05 \%$ a $0,24 \%$, com $50 \%$ de inconformidades. DIAS et al. (2009) também encontraram uma variação de $0,04 \%$ a $0,32 \%$, com três amostras de méis fora dos padrões, provenientes de Londrina e região. BRAGA et al. (2009), analisando 16 marcas de méis comerciais com registro de inspeção de Uberaba, MG, encontraram variação de 0,440\% a 6,790\%, totalizando $87 \%$ de amostras com valores superiores a $0,1 \%$.

A enzima diastase é produzida pelas glândulas hipofaríngeas das abelhas e é responsável pela hidrólise do amido. Possui alta sensibilidade ao calor e, por isso, baixos níveis de diastase indicam superaquecimento do mel (CRANE 1987). 
A legislação brasileira estabelece que a atividade diastásica deve apresentar um mínimo de oito unidades na escala Gothe (BRASIL 2000). Os valores mínimos e máximos encontrados foram de 2,61 (amostra 15) a 18,82 (amostra 16) unidades Gothe. Assim, 22,72\% das amostras (4, 6, 7, 15, 19) atingiram resultados inferiores a esse valor. Valores de diástases diminuídos estão correlacionados ao processo de desnaturação das amilases, ocorrido durante um possível tratamento térmico durante seu processamento (CRANE 1987).

CARNEIRO et al. (2015) ao pesquisarem amostras de méis inspecionados e informais constataram que $61,82 \%$ das amostras estavam em desacordo com a legislação. O valor mínimo para atividade diastásica foi de 0 unidades Gothe e o valor máximo foi de 22,7 unidades Gothe. SILVA et al. (2011) obtiveram médias para mel de apicultores de 16,60 unidades Gothe e, para méis com registro de inspeção de 15,30 unidades Gothe. LIRIO et al. (2015) obtiveram média de 8,8 unidades Gothe e, valores mínimos e máximos para atividade diastásica de 0,8 e 37,8 unidades Gothe.

O segundo componente em maior presença no mel é a umidade. E está diretamente ligada à sua qualidade, maturidade e conservação (KOBLITZ 2008). O valor máximo de umidade permitidos pela IN11/2000 é de 20\%. A variação encontrada foi de 14,3\% (amostra 7) a 19,1\% (amostra 17). Todas as amostras analisadas estão de acordo com a legislação. Produtos com altos teores de umidade podem sofrer fermentação por microrganismos osmofílicos e podem indicar uma colheita inadequada de méis nãomaduros (OLIVEIRA et al. 2015). Logo, não há indícios de processos fermentativos nas amostras analisadas.

GOMES et al. (2015) obtiveram resultados de umidade, para sete amostras do município de Soure, Arquipélago de Marajó, uma variação de $13,26 \%$ a $18,26 \%$, enquadrando todas as amostras dentro da legislação. RITCHER et al. (2011), ao analisarem 19 amostras de méis do município de Pelotas, RS, encontraram uma variação na umidade de $15,4 \%$ a $20,9 \%$ e apenas uma amostra acima dos valores estabelecidos pela IN11/2000. Em desacordo com os valores obtidos, ABADIO FINCO et al. (2010) encontraram $33,3 \%$ de amostras ultrapassando os limites da legislação para umidade. Das 24 amostras de méis analisadas da região Sul do Estado de Tocantins, obtiveram uma variação de $18,9 \%$ a $21 \%$ para umidade. BRAGA et al. (2009), ao analisarem 16 amostras de méis de Uberaba, MG, obtiveram variação de $17,3 \%$ a $20,5 \%$ de umidade, com $25 \%$ das amostras em inconformidade com a IN11/2000.

As reações de Lund, Fiehe e Lugol são consideradas análises qualitativas e complementares que podem indicar adulteração ou má conservação do mel. A reação de Lund baseia-se na precipitação de substâncias albuminóides pelo ácido tânico. Segundo a Portaria6/1985, a reação de Lund deve ser positiva, indicando mel puro, quando ocorre a formação de precipitado no intervalo de 0,6 a $3 \mathrm{~mL}$.

A detecção qualitativa de HMF baseia-se na reação de Fiehe. A adição de glicose comercial ou o superaquecimento do mel reage apresentando uma coloração avermelhada. Este composto que se forma é devido à presença da resorcina em meio ácido e é indicada como uma amostra positiva (IAL 2008). Conforme a Portaria6/1985, a Reação de Lund deve ser negativa.

Já a reação de Lugol baseia-se na reação do iodo e iodeto na presença de amido e dextrinas no mel. A reação é positiva ao apresentar uma coloração marrom-avermelhada, e indica a adição de glicose comercial e/ou xaropes de açúcar (IAL 2008). A legislação brasileira não torna a Reação de Lund uma análise obrigatória.

As amostras foram submetidas à análise destas três reações. Observou-se que na reação de Lund, $9,09 \%$ das amostras (5 e 6) não formaram precipitado, caracterizando amostras de méis adulterados. Na reação de Fiehe, $18,18 \%$ das amostras foram positivas $(4,6,7,18)$, indicando a adição de glicose comercial ou superaquecimento dos méis. Para a reação de Lugol, 9,09\% das amostras (6 e 18) apresentaram coloração marrom-avermelhada, sendo consideradas positivas devido a uma possível adição de glicose comercial ou xaropes de açúcar.

CARDOSO FILHO et al. (2011), ao analisarem 16 amostras de méis comercializados em diferentes municípios do Mato Grosso do Sul, constataram que 50\% das amostras analisadas para a reação de Lund não apresentaram a formação de precipitado dentro do intervalo indicado. Para a reação de Fiehe, 25\% das amostras foram positivas e, $31,25 \%$ apresentaram-se positivas para a reação de Lugol.

SANTOS et al. (2011), ao analisarem cinco amostras de méis do município de Itaquera, SP, observaram que para a reação de Lund, três amostras formaram precipitado inferior a $0,6 \mathrm{~mL}$; para a reação de Fiehe, quatro amostras apresentaram-se positivas e, para a reação de Lugol, duas amostras foram positivas.

DIAS et al. (2009) obtiveram resultado de quatro amostras fora do intervalo de 0,6 a $3 \mathrm{~mL}$ para reação de Lund; positividade em duas amostras para reação de Fiehe e, para a reação de Lugol, duas amostras 
positivas, em estudo conduzido com seis amostras de méis provenientes de Londrina e região.

Considerando que as legislações brasileiras e internacionais vigentes não fazem exigências quanto a realização de análises microbiológicas (KOBLITZ 2011), dez amostras apresentaram crescimento de bolores e leveduras, conforme pode ser observado na Tabela 2.

Tabela 2. Análises microbiológicas para bolores e leveduras de méis provenientes de diferentes municípios da região Sul do Brasil.

Table 2. Microbiological analyzes for molds and yeasts of honey varieties from different municipalities in the South Region of Brazil.

\begin{tabular}{ll}
\hline Amostras & Bolores e Levedura (UFC/g) \\
\hline 1 & $6,0 \times 10^{2}$ \\
4 & $9,5 \times 10^{1}$ \\
10 & $6,5 \times 10^{1}$ \\
14 & $2,5 \times 10^{2}$ \\
16 & $1,5 \times 10^{2}$ \\
17 & $2,8 \times 10^{2}$ \\
18 & $8,5 \times 10^{1}$ \\
19 & $1,2 \times 10^{2}$ \\
21 & $1,2 \times 10^{3}$ \\
22 & $4,2 \times 10^{2}$ \\
\hline
\end{tabular}

Nota: UFC/g (unidade formadora de colônia/grama). As outras amostras analisadas não obtiveram um crescimento significativo para realização da contagem padrão para bolores e leveduras.

Foram contadas as placas que apresentaram acima de cinco colônias. Os valores encontrados

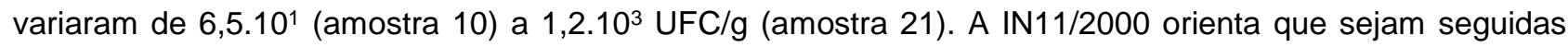
boas práticas de higiene e manipulação do produto para evitar contaminação dos produtos por estes microrganismos (BRASIL 2000). A contagem padrão de bolores e leveduras para as demais amostras apresentou valores desconsideráveis.

WENZEL (2012), ao analisar 40 amostras de méis sem selo de inspeção, do município de Picos e da macrorregião do Estado do Piauí, verificou que 22 amostras (55\%) apresentaram índice de contaminação por bolores e leveduras acima de $100 \mathrm{UFC/mL}$. LIEVEN et al. (2009), analisando 18 amostras de méis de comércio formal e informal, constataram a presença de bolores e leveduras em oito amostras $(44,44 \%)$ da região do extremo sul da Bahia.

\section{CONCLUSÃO}

Através da avaliação físico-química constatou-se que 12 amostras (54,54\%) apresentaram alguma inconformidade com os valores determinados pela legislação brasileira.

Os resultados obtidos mostram que $60 \%$ das amostras inspecionadas estão em desacordo com as especificações da legislação para a qualidade do mel, enquanto que $50 \%$ das amostras de méis não inspecionadas apresentaram-se fora dos padrões estabelecidos.

A análise microbiológica demonstrou que $45,45 \%$ das amostras apresentaram bolor e levedura. Enquanto que $30 \%$ das amostras inspecionadas e $58,33 \%$ das amostras não inspecionadas apresentaram contagem de bolor e levedura.

A fiscalização da cadeia produtiva do mel merece maior atenção a fim de proteger o consumidor em adquirir produtos adulterados ou com baixa qualidade, devido a falhas durante o processo de extração e beneficiamento. Produtos que possuem registro de inspeção devem ter um índice de reprovação menor quando comparados a produtos comercializados informalmente, pois subentende-se que são possuidores dos requisitos mínimos da qualidade do mel.

\section{REFERÊNCIAS}

ABADIO FINCO FDB et al. 2010. Propriedades físicas e químicas do mel de Apis mellifera L. Food Science and Technology 30: 706-712.

ABEMEL. 2015. Associação Brasileira de Exportadores de Mel. Setor apícola brasileiro em números. Inteligência Comercial. Disponível em: http://brazilletsbee.com.br/inteligencia_comercial_abemel_abril_2015.pdf. Acesso em: mar. 2016. 
ANDRIGHETTO AJ et al. 2009. Avaliação da qualidade físico-química do mel comercializado em Santo Augusto - RS. In: III Mostra Nacional de Iniciação Científica e Tecnológica Interdisciplinar e I Fórum Nacional de Iniciação Cientifica no Ensino Médio e Técnico. Resumos... Camboriú: UFSC - Colégio Agrícola de Camboriú.

ANVISA. 2002. Agência Nacional de Vigilância Sanitária. Resolução RDC no 259, de 20 de setembro de 2002. Regulamento Técnico sobre Rotulagem de Alimentos Embalados. Diário oficial da União.

ARAÚJO DR et al. 2006. Avaliação da qualidade físico-química do mel comercializado na cidade de Crato, CE. Revista de Biologia e Ciências da Terra 6: 51-55.

ARRUDA JBF et al. 2011. Diagnóstico da cadeia produtiva da apicultura: um estudo de caso. In: XXXI Encontro Nacional De Engenharia De Produção. Resumos...Belo Horizonte: ENEGEP. 13p.

BRAGA KA et al. 2009. Qualidade físico-química de méis comercializados no município de Uberaba. In: II Seminário Iniciação Científica. Resumos... Uberaba: IFTM. 5p.

BRASIL. 1985. Ministério da Agricultura, Pecuária e Abastecimento. Portaria no 6, de 25 de julho de 1985. Normas Higiênico-Sanitárias e Tecnológicas para Mel, Cera de Abelhas e Derivados.

BRASIL. 2000. Ministério da Agricultura, Pecuária e Abastecimento. Instrução normativa no 11, de 20 de outubro de 2000. Regulamento de identidade e qualidade de mel.

BRASIL. 2016. Ministério da Agricultura. Serviço de Inspeção Federal. Disponível em: http://www.agricultura.gov.br/assuntos/inspecao/produtos-animal/sif. Acesso em: 23 out. 2018.

CARDOSO FILHO N et al. 2011. Avaliação físico-química de méis comercializados em algumas cidades do Estado do Mato Grosso do Sul. Ensaios e Ciências: Ciências Agrárias, Biológicas e Saúde 15: 135-146.

CARNEIRO DS et al. 2015. Qualidade físico-química de méis comercializados na Cidade de Recife, Pernambuco. In: XXV Congresso Brasileiro de Zootecnia. Resumos... Fortaleza: ZOOTEC.

CHAVES WA et al. 2015. Qualidade de Mel Comercializado em Feiras Livres do Município de Teresina, Piauí. In: XXV Congresso Brasileiro de Zootecnia. Resumos... Fortaleza: ZOOTEC.

CRANE E. 1987. O livro do mel. 2.ed. São Paulo: Nobel. 226p.

DIAS JS et al. 2009. Caracterização Físico-Química de Amostras de Mel. UNOPAR Científica: Ciências Exatas e Tecnológicas 8: 19-22.

FAO. 2013. Organização das Nações Unidas para Alimentação e Agricultura, Disponível em: http://faostat3.fao.org/faostat-gateway/go/to/browse/Q/QL/E. Acesso em: 20 mai. 2016.

GOMES PWP et al. 2015. Avaliação físico-química de méis produzidos no município de Soure - Marajó - Pará. In: 14o Encontro dos Profissionais da Química da Amazônia. Resumos... Belém: EPQA.

IBGE. 2011. Instituto Brasileiro de Geografia e Estatística. Pesquisa de orçamentos familiares 2008-2009: análise do consumo alimentar pessoal no Brasil. Rio de Janeiro. 150p.

IBGE. 2013. Instituto Brasileiro de Geografia e Estatística. Produção da Pecuária Municipal. Rio de Janeiro. 108p.

IAL. 2008. Instituto Adolfo Lutz. Métodos físico-químicos para análise de alimentos. 4.ed. São Paulo: IAL. 1020p.

IOIRICH N. 1981. As abelhas, farmacêuticas com asas. Moscou: Editora Mir. 228p.

KOBLITZ MGB. 2008. Bioquímica de alimentos: Teoria e Aplicações Práticas. Rio de Janeiro: Guanabara Koogan. $256 \mathrm{p}$.

KOBLITZ MGB. 2011. Matérias-primas alimentícias: Composição e controle de qualidade. Rio de Janeiro: Guanabara Koogan. 301p.

LIEVEN M et al. 2009. Avaliação da qualidade microbiológica do mel comercializado no extremo sul da Bahia. Revista Baiana de Saúde Pública 33: 544-552.

LIRIO FC et al. 2015. Avaliação dos parâmetros físico-químicos e análise por componentes principais de méis silvestres produzidos e comercializados no Estado do Rio de Janeiro, Brasil. Infarma - Ciências Farmacêuticas 27: 8p.

MARCHINI LC et al. 2005. Análise de agrupamento, com base na composição físico-química, de amostras de méis produzidos por Apis mellifera L. no Estado de São Paulo. Food Science and Technology 25: 8-17.

MORETI ACC et al. 2009. Características físico-químicas de amostras de méis de Apis mellifera L. do Estado do Ceará, Brasil. Ciência e Agrotecnologia 33: 191-199.

OLIVEIRA ENA \& SANTOS DC. 2011 Análise físico-química de méis de abelhas africanizadas e nativa. Revista Instituto Adolfo Lutz 70: 132-138.

OLIVEIRA KMG et al. 2015. Análises das características físico-químicas do mel de abelhas comercializado na região noroeste do Paraná. In: 24ํEncontro Anual de Iniciação Científica. 4º Encontro Anual de Iniciação Científica Júnior. Resumos... Paranavaí: UEP. 4p.

PEREIRA JDM et al. 2015. Análise físico-química e microbiológica de amostras diferentes de mel comercializadas em Maringá (PR). Revista Baiana de Saúde Pública 39: 356-369.

PINTO CCOA \& LIMA LRP. 2010. Análises físico-químicas de méis consumidos no Valo do Aço/MG. Farmácia \& Ciência 1: 27-40.

RITCHER W et al. 2011. Avaliação da qualidade físico-química do mel produzido na cidade de Pelotas/RS. Alimentos e Nutrição Araraquara 22: 547-553.

SANTOS AB et al. 2011. Determinação da autenticidade dos méis vendidos nas feiras livres e comércios populares. Brazilian Educational Technology: research and learning 2: 135-147.

SEBRAE 2007. Serviço Brasileiro de Apoio às Micro e Pequenas Empresas. Apicultura: Manual do agente do desenvolvimento rural. Brasília: SEBRAE. 186p.

SEBRAE 2011. Serviço Brasileiro de Apoio às Micro e Pequenas Empresas. Boletim Setorial do Agronegócio. 
Apicultura. Recife: SEBRAE. 15p.

SILVA RA et al. 2006. Composição e propriedades terapêuticas do mel de abelha. Alimentos e Nutrição Araraquara 17: 113-120.

SILVA MBL et al. 2011. Qualidade de méis produzidos por apicultores e méis provenientes de entrepostos registrados no Serviço de Inspeção Federal. Arquivo Brasileiro de Medicina Veterinária e Zootecnia 63: 1043-1045.

WELKE JE et al. 2008. Caracterização físico-química de méis de Apis mellifera L. da região noroeste do Estado do Rio Grande do Sul. Ciência Rural 38: 1737-1741.

WENZEL JM. 2012. Avaliação da qualidade microbiológica do mel não inspecionado comercializado na cidade de Picos e macrorregião do Estado do Piauí. Monografia (Bacharelado em Nutrição). Picos: UFPI. 28p. 